\title{
Portrait Masks, Appropriated Space, and an Overseas Art Experiential: Nature as Critical Catalyst in the Practice and Training of Art Therapy
}

\section{肖像面具，挪用空间与海外体验式艺术学习 : 自然作为艺术治疗实践和培训的 关键催化剂}

\author{
Ronald P. M. H. Lay \\ LASALLE College of the Arts, Singapore
}

\begin{abstract}
This article asserts that there are current trends in the practice and training of art therapy that are influenced and inspired by technologies, space, and art. Culture enriches these intertwined constructs demanding that practice and training are duly informed, especially within the contexts in which these are applied. The article is consolidated through a practitioner-based reflective account of the author's experience of leading a weeklong overseas trip with postgraduate art therapy students from Singapore to Bali, Indonesia. Acknowledging the multilayered processes involved with experiential learning, the focus pivots around one structured and supervised art experiential within an appropriated space in nature. Portrait masks were constructed, worn, and photo-documented within the space. Participant understanding of technologies, space, art, and artmaking were challenged, leading to enriched discourse around these constructs and how best to integrate these emerging trends within their own practice and training, as well as their identities as artist and art therapist with consideration to culture.
\end{abstract}

Keywords: art therapy, technology, portrait masks, space, Southeast Asia

\section{摘要}

本文认为，目前艺术治疗的实践和培训趋向于受到技术、空间和艺术的影响和启发。 文化丰富了这些互相交织的概念，特别在应用技术、空间和艺术的情境下， 要求以适当的方式让人们了解实践和培训。这篇文章基于实践者反思性的描述， 对作者带领艺术治疗研究生从新加坡到印度尼西亚巴厘岛进行为期一周的 海外旅行的经验进行整合。认识到体验式学习所涉及的多层次过程，文章的重点 围绕着在自然界一个适当的空间里进行的结构化和督导性的艺术体验。参与者制作、 佩戴肖像面具，并在空间内进行拍照记录。参与者对技术、空间、艺术和艺术创作的理 解受到了挑战，引发了围绕这些概念以及如何最好地在自己的实践和培训中整合这些新 兴趋势的丰富讨论，并且以文化为考量论述了作为艺术家和艺术治疗师的身份。

关键词: 艺术治疗，科技，肖像面具，空间，东南亚 


\section{Introduction: Preoccupations with Technologies}

Preoccupations with technologies, from gadgets and hardware to apps and social media, seem to have infiltrated all aspects of our being and is evidenced in the various inter-relational aspects of our personal, professional, academic, and artistic pursuits. Intertwined as they are, and as technologies evolve, there is great potential in art therapy (Belkofer \& Belkofer, 2018; Carlton, Sit \& Yu, 2018; Choe \& Carlton, 2019; Horovitz, 2019; Lay, 2020; McNiff, 2018). The inherent creativity involved in the discipline of art therapy permits the art therapist to see the bigger picture and to strategically evolve their practice in ways that not only sustains currency but also optimizes the therapeutic dynamic. Similarly, and just as critical for the art therapist, is the compelling need to progress one's art practice so as to further stimulate and stretch one's imagination and proficiency in using a broader range of materials and media, as well as the understanding of physical, psychological and social spaces in which meaningful encounters can be experienced (Backos \& Carolan, 2018; Choe \& Carlton, 2019; Huss, 2015; Kapitan, 2014; Lay, 2018; McLachlan, 2017; Whitaker, 2021).

Envisaged through a practitioner-based approach to augmenting art therapy training, this article aims to reflectively spotlight one creative and structured arts experiential with 14 students on a supervised overseas trip to Bali, Indonesia, in 2019 (Figure 1).

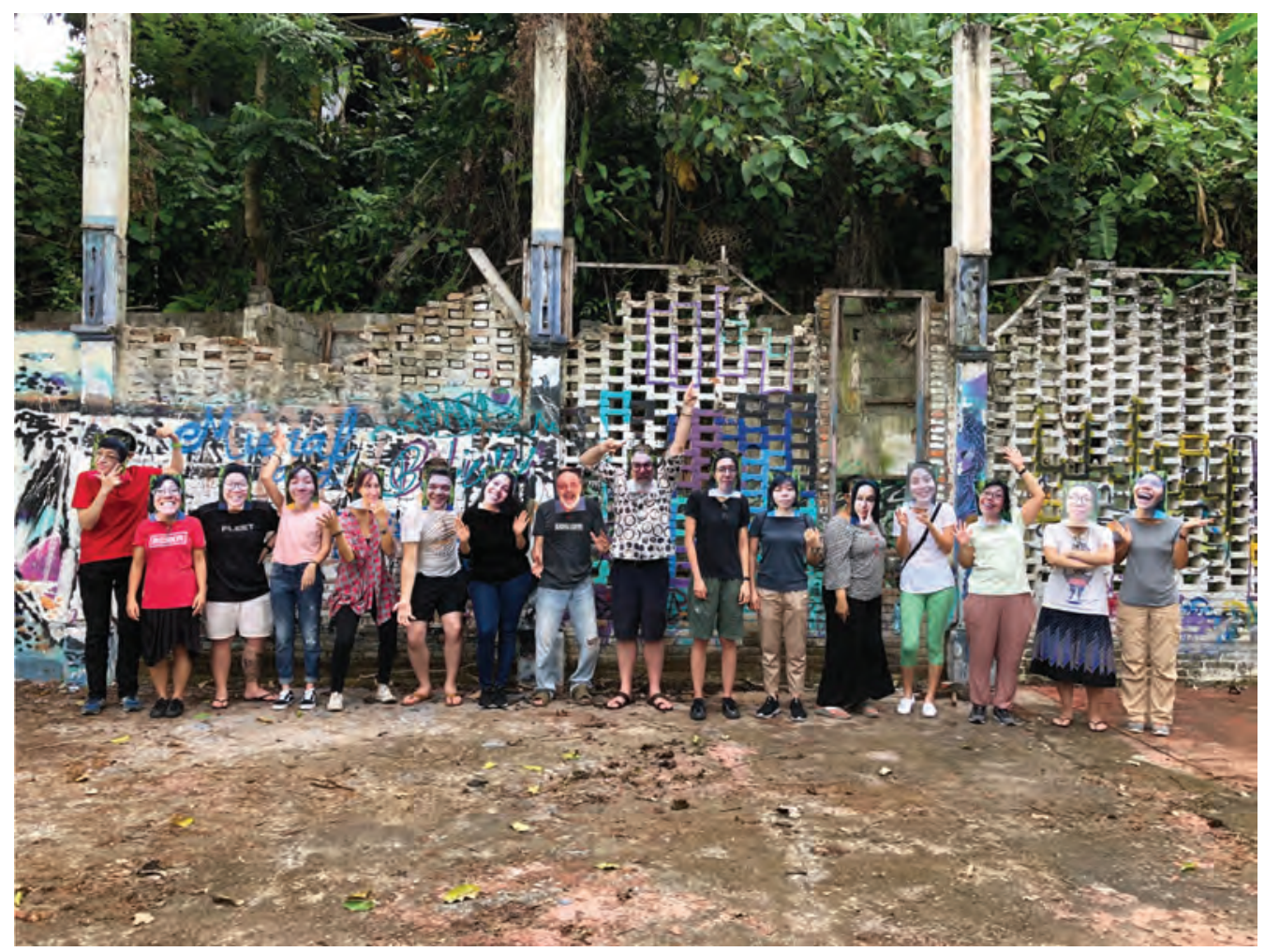

FIGURE 1 | Groupie I, portrait masks in the space (photograph by R. Trevelyan). 
This experiential, involving portrait masks and posturing within nature, is prioritized, as it was a rather profound and dynamic experience for all involved, and there are significant implications for art therapy training and practice as well as for art and artmaking. This multitiered arts experiential was potent in challenging one's perspectives on emerging and contemporary art and art therapy practice; the consideration of space and environment - physically, symbolically, and virtual; the acknowledgement of one's culture and identity, the culture of others as well as cultural understandings of art, art traditions, and art therapy; the concept of self with regard to one's multiple roles including artist, therapist, trainee, and researcher; and one's relationship with technologies. Each of these five aspects were further influenced by and engaged with through a purposeful immersion into various outdoor environments, sensitively cradled in the wisdom of nature (Figure 2).

Since 2015, the MA Art Therapy program at LASALLE College of the Arts in Singapore has provided overseas student trips focusing on art, culture, and mental health (Lay, 2020). These trips provide enriched and immersive experiences for students, opportunities for cultural exchange and dialogue, visits and workshops to stimulate art practice, and include social engagement wherein the students proactively plan and then facilitate open art studio sessions with participants from local settings (Lay, 2020).

Singapore is culturally rich and diverse; however, something rather profound happens when students travel overseas to experience other cultures, other arts practices, and other groups of people firsthand. All overseas student trips are planned months in advance, are voluntary, and reside outside of the academic semester; they expand the student's insights, understanding, and application to a range of contexts and serves to complement their intensive two-year training. Thus far, travels have included the

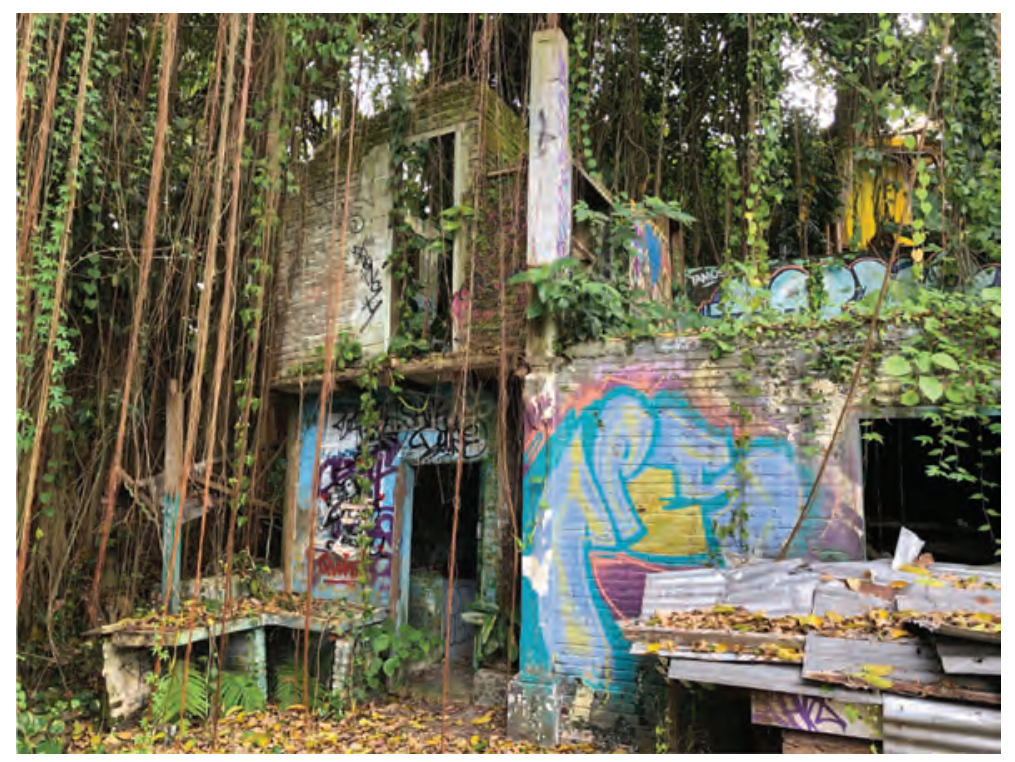

FIGURE 2 | Art Zoo (photograph by R. Lay). 
United Kingdom, the United States, Malaysia, and Indonesia. Each trip is supervised and led by the MA Art Therapy Programme Leader (the author of this article).

For context, the 2019 trip was the second visit to Bali and built upon the activities, relationships, and partnerships that were established in 2018. The success of the first trip saw the number of student participants double in size, from 7 in 2018 to 14 in 2019; there were 8 students from the year 1 cohort and 6 students from the year 2 cohort. The majority of the students were from Singapore, and there were three students from India, South Africa, and Vietnam. All students provided consent to include a groupie (Figure 1), and several others consented to the inclusion of photographs of them wearing their and other participants' portrait masks (Figures 3 and 4).

The resonate thrusts of this article, therefore, are centralized around art therapy training in Southeast Asia (Singapore), the constructs of embodiment and space (outdoors/indoors), and a calculated response to technologies and how these may be meaningfully introduced within art and art therapy practice. Consolidated from the author's first-hand account of conceptualizing and co-facilitating this experiential with Bali-based Canadian artist, David Trevelyan, and in collaboration with his wife, Rani, this article intends to dialogue our concerted attempt at creatively addressing our growing concerns over addictions related to technologies and the critical role of art, artmaking, human connection, and of being in nature. David's prolific career as an artist, sculptor, and mask-maker anchored the core art-making aspects of the annual weeklong trips to Bali, and his outdoor home studio provided the essential creative space for a majority of the experiential workshops.

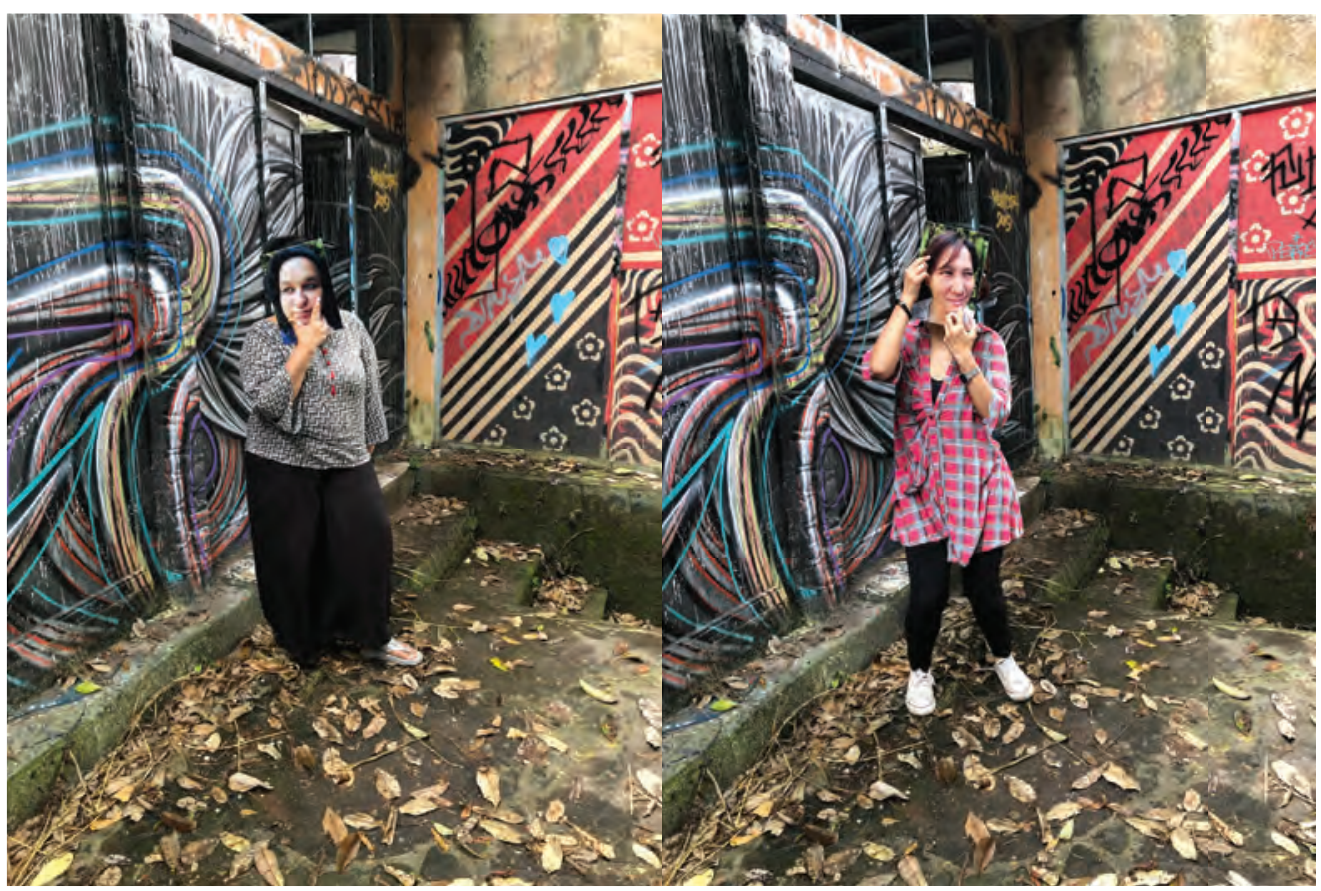

FIGURE 3 | Posturing with their own portrait masks (photograph by R. Trevelyan). 


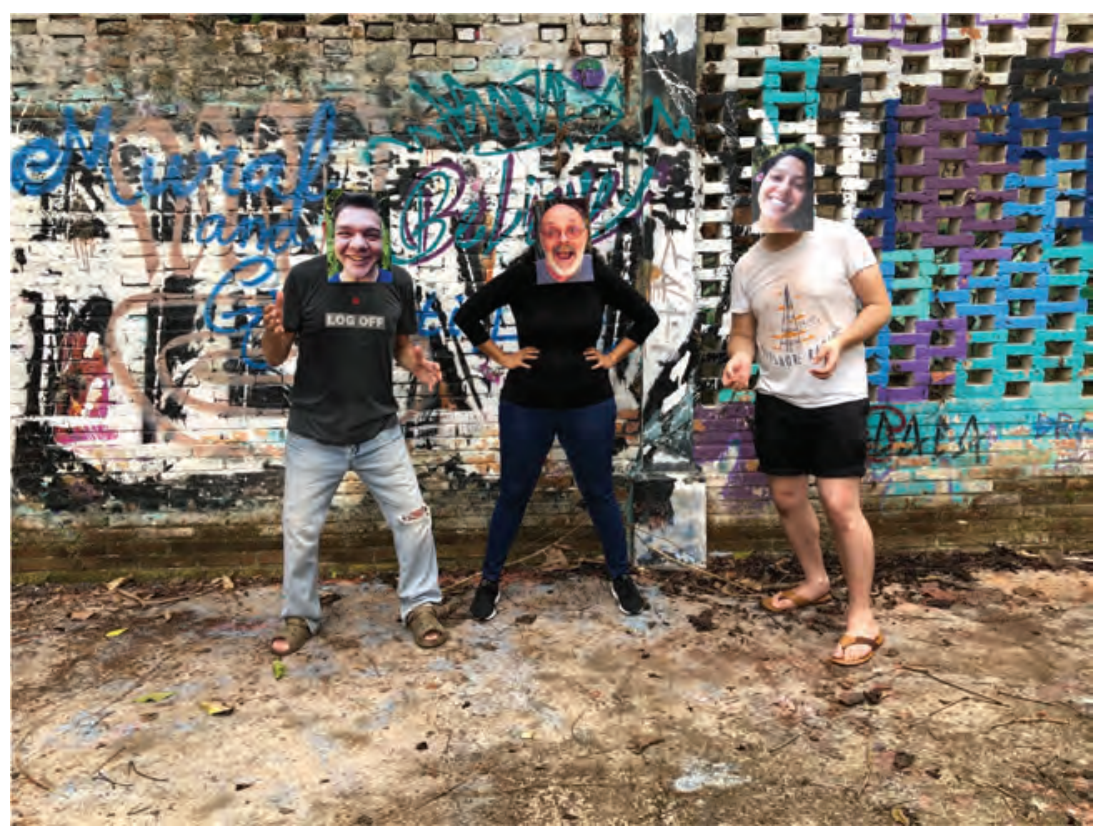

FIGURE 4 | Groupie II, wearing each other's portrait masks (photograph by R. Trevelyan).

\section{Scratching the Surface: Constructs of Technologies/Portraits/Space}

This section surfaces the concepts of space, technologies, portraits, and how, together, they can contribute to an integration of body-mind-spirit as part of one's practice. Often described as a hybrid discipline, it is not surprising that art therapy intuitively expands to take into account diverse interests, developments, and trends associated with various communities, cultures, and geographical regions; understandably, this is part of ethical practice (Atkins \& Snyder, 2018; Backos \& Carolan, 2018; Huss, 2015; Kapitan, 2014; Lay, 2018, 2020; McLachlan, 2017; Park, 2019; Whitaker \& Riccardi, 2019).

Recent literature suggests strong interests in nature and a return to the outdoors, an acknowledgement that technology is here to stay, that we must somehow integrate this within our service delivery, and that there is a resurgence in prioritizing creativity, imagination, and play in art therapy practice and training (Atkins \& Snyder, 2018; Belkofer \& Belkofer, 2018; Carlton et al., 2018; Horovitz, 2019; Hunter, 2012; Lay, 2020; Whitaker, 2021). Training that involves strong reflective processes certainly validates understanding as well as insights that we are yet to uncover-especially relevant as we move between actual and digital realities; reflective questions do lead to answers, however, they also lead to more questions (Backos \& Carolan, 2018; Carlton et al., 2018; Lay, 2020; Whitaker \& Riccardi, 2019).

As with all learning environments, the physical space must be carefully considered to ensure everyone's physical, psychological, and emotional safety. As part of a multipronged approach, students are challenged to consider their own experience in the 
here and now with the various roles they assume (trainee, artist, practitioner, researcher), make links to the client-therapist experience within the therapeutic encounter, expand their perspectives on what is and what can be, enhance their creative self-expression and art practice, and reflect upon and learn more about their own culture and the culture of others. Creating art and being in new spaces/environments stimulate the art therapy trainee and practitioner to expand their notion of where and how art therapy can happen, which, in essence, evolves practice (Carr, 2020; Lay, 2020; McLachlan, 2017; Whitaker \& Riccardi, 2019). The metaphors invoked by space are rich and can be further unpacked and dialogued and can be represented and/or experienced through art and by physically being in that space (Whitaker, 2021).

Technologies are influencing the way we communicate, they impact our interrelationships and they are even shaping our creative self-expression, our identities, and our understanding of where we locate ourselves within space (Belkofer \& Belkofer, 2018; Carlton et al., 2018; Choe \& Carlton, 2019; Hunter, 2012; Lay, 2020). The potential of technologies to (re)connect with others can be effectively tapped into given how experiences can be shared and re-experienced through a blend of in-person and online activity (Belkofer \& Belkofer, 2018; Carlton et al., 2018; Lay, 2020).

Metaphors are layered and can be uniquely individual and/or universal depending upon how they are expressed, understood, and unpacked within a given context and with a given population (Gambrel, Burge, \& Sude, 2020). Journey implies movement and can be physical, emotional, psychological, or transformational; a narrative of one's journey can be generated and communicated through a range of media. Oftentimes, the metaphor of journey is utilized in art therapy, given the wealth of associations and application across various experiences, conditions, and cultures. Technologies have allowed us to remotely experience sensations along our journey, whether we are referring to our actual life course, being in spaces and natural environments, or to a more metaphorical or symbolic journey (Hunter, 2012; Kapitan, 2014; Whitaker, 2021).

Portraits can and have been made with technologies, and these too are finding their way into the therapeutic encounter. Typically, such portraits are referred to as selfies when taken by an individual themselves and as groupies when the photograph involves a selfie as part of a group (Wang, Yang, \& Haigh, 2017). These types of portraits, as well as those created through other media for that matter, when reviewed and reflected upon within art therapy, can allow the client to explore the context(s), experiences, memories, and associations in a purposeful and meaningful manner and can even challenge and/ or assert power differentials through the act of who and what is seen, looked at, and acknowledged (Alter-Muri, 2007; Carr, 2020; Huss, 2015; Kopytin, 2018). Creating selfimages may be disturbing and confrontational for some people; therefore, it is critical that there is purpose and rationale behind any directive and that the art therapist is duly informed so as to structure, support, and contain any dynamics that might surface and/ or to decide when working with portraits is not appropriate in a given context (AlterMuri, 2007).

Research into the use/over use of technologies, including the taking, posting, and sharing of selfies/groupies, is emerging, and there have been suggested links to mental health and wellbeing (Balakrishnan \& Griffiths, 2018; Rumpf, Browne, Brandt, 
\& Rehbein, 2020; Wang et al., 2017). Mindfulness can be strategically introduced into our practice as a way to balance the impact of technologies, and this can be further achieved by going into nature; in fact, nature is central to the art of many cultures, including those throughout Asia (Atkins \& Snyder, 2018; Gambrel et al., 2020; Hunter, 2012; Park, 2019; Whitaker, 2021).

\section{Constructed Portrait Masks, Posturing, and the Art Zoo: A Practitioner- based Account}

In advance of the overseas trip with students, I made a reconnaissance visit to Bali as part of the overall planning. David, Rani, and I wanted to identify and secure an outdoor space, unlike any space that could be experienced in Singapore, that could evoke a range of emotional responses, intrigue, and perhaps psychological dimensions as part of our portrait mask experiential. The multipurpose outsider art studio/gallery/ living space that we had accessed the year previous was no longer in operation, and so we needed to find another stimulating environment.

After several hours of visiting a range of spaces around Bali, we came across what we coined the Art Zoo (Figure 2). This location was selected for many reasons: it was the total opposite of what characterizes spaces in Singapore-it was wild, derelict, overgrown, and encased in graffiti; it was a relatively unknown space to the facilitators and to the students; it overtly evidenced the power and intrigue of nature; the rich metaphors and associations of this space could be uniquely experienced by all participants. Once the students arrived in Bali, the experiential was delivered in three phases at different points throughout the week: (1) a morning visit to a culturally rich and diverse mask and puppet museum, the Setia Darma House of Masks and Puppets (http://maskandpuppets.com); (2) an afternoon workshop at David's outdoor studio; and (3) an afternoon installation with performance in the Art Zoo. This not only exposed the students to a vast array of cultural and traditional artforms, but it also stimulated further discussion on the purpose and function of masks as well as how art therapists have used masks within therapeutic encounters. Our masks, however, would involve our own portraits taken by Rani with a digital camera, printed by a laser printer in color onto adhesive paper, and then constructed into a wearable form on cardstock.

On the afternoon of the experiential, and as a full group, we surveyed the space and came across an ideal platform to conduct and photo-document our individual portrait mask performance (Figure 5). Although playful, it was necessary to orchestrate the space so that each participant could safely wear their mask (there were no eye holes resulting in some participants becoming disoriented), engage in some experimental movement and posturing within the environment, and then have these photographed as selfies and groupies (Figures 3 and 4).

The experience was received with a wide range of reactions and giggles, and many acknowledged that it was a rather surreal experience to actually wear a portrait mask of themselves and to engage in movements within an unfamiliar space. Many found the blend of natural/technological aspects of this experience - digital photograph, the mask materials, and engaging in nature-intriguing, as this further stimulated their 


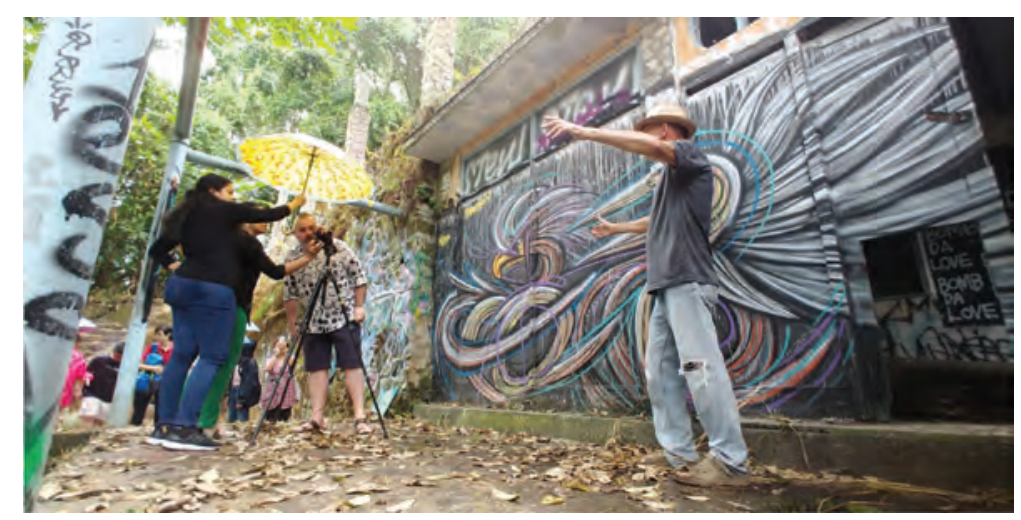

FIGURE 5 | Setting up the photoshoot within the space (photograph by L. H. Ong).

own reactions to taking selfies/groupies, fostered ideas for future art projects, and made them realize how being in nature was inspiring.

The initial questions for the design of the portrait mask experiential were the following: What are the perceptions of art therapy trainees posturing with their own constructed portrait mask within an unfamiliar environment and how might their experiences be translated into their art and art therapy practice? During the trip itself, we had several rich and layered discussions around this experiential, including the construct of mask within Asian cultures. Themes around self-perception, presence and safety within spaces and environments, the healing potential of being outdoors in nature, and the sense of play and discovery while co-creating, co-experimenting, and co-experiencing were enlightening and served to push the potential of art, art-making, and art therapy practice within a range of contexts. Throughout the week and during various contemplative ruminations, David's mantra log-off and tune-in focused our attention and reminded us to be present, in the moment, and to allow ourselves to be reignited by the power of nature and to consciously become reconnected with humanity in renewed ways.

It is apparent that the students found the experience interesting, memorable, and impactful. For some students, their perception and understanding of their own culture, art traditions, use of technologies, and even their own identities were challenged and reflected upon in evocative ways. Co-experiencing and actively engaging with the students and David allowed me to not only stretch how I perceive the potential of art, technologies, and the experiencing of space, but also how to enhance the teaching and learning within art therapy in ways that are transformative, current, and responsive to the contexts within which I find myself. My own experiments with my portrait mask were unnerving and uncomfortable, given my tendency to being reserved; however, it was reassuring to also embrace this novel experience with the students, as it seemed to shift perceived power differentials and allowed for memories that we still reminisce about. Much thought and deliberation went into the purposeful design, development, and facilitation of this experiential, and there was much to reflect upon both then and now. 
A powerful revelation that still resonates with me is that even with well-thoughtthrough experientials that have been carefully constructed and attended to in regard to ensuring safe spaces/environments, ethics, best practices, and respect to culture, there will always be complex intricacies that may be innocently missed. For example, we had deliberately decided to not discard our masks by burning at the end of the week (a practice engaged in by one of our collaborators), this turned out to be an appropriate and respectful decision in regard to some of the cultures represented in our group. However, inviting the group to pose with their portraits in their hands was rather disconcerting for some participants, as this was reminiscent of holding a loved one's death photograph. Understandably, this resulted in even more discussion around cultural awareness, sensitivity, and humility. Admittedly, it was with great sensitivity and ethical deliberation that I invited participants to consider consenting to the use of our groupie, of us wearing — not holding — our portrait masks used as Figure 1.

The experiences and the responses to this experience are riddled with potent metaphors, associations, and perhaps even debate. A third trip was planned to Bali in 2020, and this would have extended and evolved the experiential; however, as with many aspects of planned activity during the global pandemic, the trip needed to be cancelled until further notice.

\section{Final Thoughts}

Introducing novel and innovative experiences as part of one's postgraduate art therapy training enhances the teaching and learning. It also serves to illuminate the potential of art and art therapy practice that extends to the environments in which it transpires (Whitaker, 2021). Art therapists need an understanding of cultures, including those involving technologies, and how these are manifested within art and the therapeutic encounter (Backos \& Carolan, 2018; Choe \& Carlton, 2019; Huss, 2015; Lay, 2018; Park, 2019; Whitaker \& Riccardi, 2019). Ongoing research into the use of technologies, including selfie-related behavior, is needed given its cultural and larger societal implications as well as its potential impact on mental health and wellbeing (Balakrishnan \& Griffiths, 2018; Rumpf et al., 2020; Wang et al., 2017). Technologies have entered the therapeutic arena, and it is up to the art therapist to navigate how best to make use of this in ways that are creative, effective, meaningful, relevant, and ethical within the contexts they find themselves in (Belkofer \& Belkofer, 2018; Carlton et al., 2018; Choe \& Carlton, 2019; Horovitz, 2019; Kapitan, 2014; Lay, 2020; Rumpf et al., 2020). Just as technologies are to be negotiated within art therapy, nature must also be sensitively navigated so that our senses can be experienced, felt, and recalibrated and that we can be further grounded as part of our more global journey (Hunter, 2012; Whitaker, 2021).

There are limitations to this current discussion; however, it is believed that the primary aims of conceptualizing this articulation of a complicated art experiential provided to art therapy trainees as part of an overseas trip were achieved. The art, the portrait masks, our selfies and groupies, and the videos that captured our activity within 
the Art Zoo are all valid and rich data, and they form what McNiff (2018) constitutes as art-based research. Future articles will devote themselves to advanced and systematic discoveries and will involve the unpacking of the artifacts themselves. Along this vein, areas for future research and experiential learning could involve a more in-depth use of masks within art and art therapy practice and training and could include collaboration with other arts practitioners and arts therapists.

Portrait masks are personal, potent, revealing, confrontational, and rich. The potential of portrait masks as both an art practice and a therapeutic intervention are promising; however, it is imperative that the artist/art therapist do their due diligence to delve deep into the history, traditions, customs, cultures, and therapeutic connotations prior to extending these to others. In the meantime, it was unanimously agreed that something rich and transformative occurred during the 2019 overseas trip, much of it stemming from the various art experientials, including the one described herein. Since this trip and at the time of penning these thoughts, there have been considerable and significant shifts to our realities given the long-lasting global pandemic and the essential need to shift much of what we do online. Nonetheless, trajectories will continue to be charted, and I am confident that technologies will take an even more critical role in art and art therapy and that nature will continue to act as a critical catalyst in evolving the discipline.

\section{Acknowledgements}

The vision of a project is often inspired by the creativity and passion of one and then contagiously embraced by others. For this, David and Rani Trevelyan must be acknowledged, as they were the initial spark of this cross-national and multiyear collaboration. The aspects of this unique partnership, between the Trevelyan's and the MA Art Therapy program at LASALLE College of the Arts in Singapore, took place reciprocally in both Singapore and Indonesia since 2016.

I am grateful to all 14 art therapy trainees who participated in the 2019 overseas trip to Bali and for their kind consent to include them in this consolidated reflection of that important experience; a special thank-you is also extended to Alex C. Koen, Ong Leng Hong, Sarvatmika Rajeev, Vaishnavi B. Dinakar, and Yoko Choi Chi Mei. Our stay in Bali was further enriched through the generous care and involvement of local culture and wisdom extended from the Pondok Cocoa Learning Retreat team, through the leadership of Heather Brown. LASALLE College of the Arts has been generous with their ongoing support of this project as well as the internationality of the teaching and learning.

\section{About the Author}

Ronald P. M. H. Lay, EdD (candidate), MA, AThR, ATR-BC, is the MA Art Therapy Programme Leader at the School of Creative Industries, Faculty of Fine Arts, Media and Creative Industries, LASALLE College of the Arts, Singapore (www.lasalle.edu. sg). Email: ronald.lay@lasalle.edu.sg 


\section{References}

Alter-Muri, S. (2007). Beyond the face: Art therapy and self-portraiture. The Arts in Psychotherapy, 34, 331-339. https://doi.org/10.1016/j.aip.2007.05.002.

Atkins, S., \& Snyder, M. (2018). Nature-based expressive arts therapy: Integrating the expressive arts and ecotherapy. Routledge.

Backos, A., \& Carolan, R. (2018). Art therapy pedagogy. In R. Carolan \& A. Backos (Eds.), Emerging perspectives in art therapy: Trends, movements and developments (pp. 48-57). Taylor \& Francis.

Balakrishnan, J., \& Griffiths, M. D. (2018). An exploratory study of "selfitis" and the development of the Selfitis Behavior Scale. International Journal of Mental Health and Addiction, 16, 722-736. https://doi. org/10.1007/s11469-017-9844-x.

Belkofer, K., \& Belkofer, C. (2018). Interpersonal downloading: The relational and creative impacts of technology and new media in therapy. In C. Malchiodi (Ed.), The handbook of art therapy and digital technology (pp. 58-73). Jessica Kingsley Publishers.

Carlton, N., Sit., S., \& Yu, D. R. (2018). Transcending media: Tangible to digital and their mixed reality. In R. Carolan and A. Backos (Eds.), Emerging perspectives in art therapy: Trends, movements and developments (pp. 74-90). Taylor \& Francis.

Carr, S. M. D. (2020). Portrait therapy: Supporting client voices of self-identity. Art Therapy: Journal of the American Art Therapy Association, 37(4), 177-184. https://doi.org/10.1080/07421656.2020.1827879

Choe, N. S., \& Carlton, N. R. (2019). Behind the screens: Informed consent and digital literacy in art therapy. Art Therapy: Journal of the American Art Therapy Association, 36(1), 15-21. https://doi.org/ 10.1080/07421656.2019.1565060.

Gambrel, L. E., Burge, A., \& Sude, M. E. (2020). Creativity, acceptance, and the pause: A case example of mindfulness and art in therapy with an adolescent. Journal of Creativity in Mental Health, 15(1), 81-89. https://doi.org/10.1080/15401383.2019.1640151.

Horovitz, E. G. (2019). Apps, telehealth, and art therapy: Online treatment and ethical issues for the digital age. In A. Di Maria (Ed.), Exploring ethical dilemmas in art therapy: 50 clinicians from 20 countries share their stories (pp. 242-252). Routledge.

Hunter, M. R. (2012). Reflections of body image in art therapy: Exploring self through metaphor and multimedia. Jessica Kingsley Publishers.

Huss, E. (2015). A theory-based approach to art therapy. Routledge.

Kapitan, L. (2014). Re: Invention and realignments of art therapy. ATOL: Art Therapy OnLine, 5(1). https:// doi.org/10.25602/GOLD.atol.v5i1.328.

Kopytin, A. (2018). Photo-art therapy. In C. Malchiodi (Ed.), The handbook of art therapy and digital technology (pp. 106-126). Jessica Kingsley Publishers.

Lay, R. P. M. H. (2018). East/West nature of ANZACATA: A perspective on the significance of international connections while asserting Southeast Asian relevance and context in practice and in postgraduate art therapy training. Creative Arts in Education and Therapy: Eastern \& Western Perspectives, 4(2), 87-96. https://caet.inspirees.com/caetojsjournals/index.php/caet/article/view/133.

Lay, R. P. M. H. (2020). Championing art in art therapy training: A multidimensional art collaboration in Southeast Asia. Canadian Journal of Art Therapy, 33(2), 80-88. https://doi.org/10.1080/26907240.202 0.184437 .

McLachlan, C. H. (2017). Art therapy caves: Linking community art to a therapeutic space. Canadian Art Therapy Association Journal, 30(1), 4-10. https://www.tandfonline.com/doi/full/10.1080/08322473.20 17.1303938.

McNiff, S. (2018). Using digital media in art-based research. In C. Malchiodi (Ed.), The handbook of art therapy and digital technology (pp. 332-347). Jessica Kingsley Publishers.

Park, S. (2019). Translation of the therapeutic language: Can one teach or practice art therapy ethically without considering culture? In A. Di Maria (Ed.), Exploring ethical dilemmas in art therapy: 50 clinicians from 20 countries share their stories (pp. 76-82). Routledge.

Rumpf, H-J., Browne, D., Brandt, D., \& Rehbein, F. (2020). Addressing taxonomic challenges for Internet Use Disorders in light of changing technologies and diagnostic classifications. Journal of Behavioral Addictions, 9(4), 942-944. https://doi.org/10.1556/2006.2020.00094. 
Wang, R., Yang, F., \& Haigh, M. M. (2017). Let me take a selfie: Exploring the psychological effects of posting and viewing selfies and groupies on social media. Telematics and Informatics, 34(4), 274-283. https://dx.doi.org/10.1016/j.tele.2016.07.004.

Whitaker, P. (2021). The art of walking: Composing landmarks, performing territory. In D. Wong \& R. Lay (Eds.), Found objects in art therapy: Materials and process (pp. 39-55). Jessica Kingsley Publishers.

Whitaker, P., \& Riccardi, M. (2019). Public relations: Art therapy pedagogy out of bounds. Canadian Art Therapy Association Journal, 32(2), 104-114. https://doi.org/10.1080/08322473.2019.1667170. 